\title{
Adult Obesity in Nigeria (The Cultural Influence)
}

\author{
Article by Adebayo Kazeem \\ Master of Public Health, Texila American University, Nigeria \\ Email: kazie2005@yahoo.com
}

\begin{abstract}
Obesity has become one of the major global problems, its emergence has created a lot of headaches griping the whole continent, (Africa) and yet on the rise, there are 120,000 death related to obesity in United States in 2010, according to WHO, Overweight and Obesity related conditions are the second leading of preventable death after tobacco smoking, It is also listed that obese children are more likely to stay obese into adulthood and more likely to die from any non communicable disease before the age of 55 than their thinner counterpart.
\end{abstract}

Keywords: Disease, Obesity, Culture, overweight, activity,

\section{The Historical Pathway to Obesity}

In the early mid - twentieth century nobody give a damn, no serious attention was paid to obesity, but as human race started to settled down to a new life after the ravage and exit of second world war, a rise in technology advancement gave birth to production and accessibility of various type of food in abundance, ranging from farm produce to quick and fast food joints and Men begun to eat their way to the grave.

The physical activity was also on decline as a result of lack of exercise, Men barely take a long walk as there are inventions of fast moving mobiles like motor bike, Tricycle, Short distance Train services, Automobiles and so on. the replacement of hard labour on factory site with automated machineries is among all the reason that made Man burn less calories, and it was initially looking good, Man was increasing in weight and flourishing, But by late sixties the gradual emergence of obesity being linked to stigmatisation, low productivity and non communicable diseases like Chronic Nephritis, Diabetes, Hypertension, and Heart diseases, what was considered good then became bad and now very ugly.

\section{The Literature Review:}

But it is getting worse, World Health Organization and the rest of stake holders in Public Health are making frantic efforts to catch up with the menace and prevalence of Obesity globally, the trend is alarming! In 2008 the statistics of overweight children under the age of five is estimated to be above 42 million globally, In United States alone 34.5\% adults (age $20 \mathrm{yrs}$ and above) are overweight, $36.7 \%$ are Obese and 7.2 are extremely obese.

Over here in Nigeria Obesity is visible, although obese records are very scanty due to poor awareness of the danger it poses to the society, However in 1996 World health Organization hinted that one third of African women and one quarter of African men are estimated to be overweight, and it was also predicted by WHO that by 2015 the figure would have increased to $45 \%$ and $32 \%$ respectively, Particularly in urban settings in Nigeria Obesity and overweight is now seen to be on the increase.

Definition: Obesity is defined as the accumulation of excess fat in adipose tissue of the body that can cause adverse effect on one's health and can even lead to life threatening. While Overweight precedes obesity, the former can come from other cause like fluid retention in the body or irregular development of muscles.

WHO said a BMI (Body Mass Index) greater than or equivalent to $25 \mathrm{~kg} / \mathrm{m} 2$ is overweight, while a BMI greater than or equivalent to $30 \mathrm{~kg} / \mathrm{m} 2$ is obesity. Therefore BMI is defined as a person's weight in kilogram divided by the square of his height in meter $(\mathrm{kg} / \mathrm{m} 2)$. 
South American Journal of Public Health

Special Edition May 2016

\section{Obesity: The Cultural influence}

Culture is one of the major reason obesity is prevalent and thrive among black race, in Nigeria obesity is the societal impression of a good life, it is culturally and socially acceptable among Nigerians, it is never considered a disease to be fat! A fat woman in Nigeria relish her body weight and accept it as a gift of nature, she considers it as an achievement, the fulfilment of her heart desire.

\section{The Cultural Influence (continued)}

In developing countries like Nigeria a fat woman is approved in society, she is looked upon with favour and accepted by all. In Nigerian culture, fatness is synonymous with prosperity, fame and good health. The fat ones are the favoured and healthy ones. She has prospect of more suitors and patronage, as a result the frustration is high among thin women, the society look down on them, they want to get fat, and they will do all they can to achieve this, it is what the society wants. This is a societal belief; obesity is deeply rooted in our culture.

The Big is Beautiful: Cultural belief is playing a major role in the rapidly growing obesity epidemic in Nigeria. The migration of women from rural to urban areas has been associated with significant life style changes, a black woman belief she must eat very well abroad and put on a lot of weight so that when visiting her rural home, the big is beautiful approach is being appraised by compliments and accolades she will received from friends and relatives they will say 'well done, you are doing well, you are the true daughter of your mother!

Being thin in Nigeria is associated with hardship, a troubled life, a life that is ravaged with illness like Tuberculosis, HIV/AIDs, and if one intends to engage in physical activities like taking a long walk, a lot of people will not understand because it is not in our character. It is a culture mentality.

\section{The Fat is Fertile}

Unlike the developed countries where obese faces a social pressure of stigmatization, unemployment, rejection, where a thin white woman can never be too thin. The reverse is the case in Nigeria a black obese woman commands a lot of respect and dignity, she is being desperately sought out by men looking for children with the cultural belief that the fat is fertile "Omo po ninu e" meaning Her womb is endowed with plenty children, overweight and obese women are hot cakes, always in high demand in the society.

\section{Slimness is Stinginess}

Men are not left out either, weight gain among men is also regarded as a sense of achievement, having a protruded belly is one of the thing that qualify a man as a socialite, as a Nigerian if you have not got a pot belly you cannot fit-in into a social circle as the saying goes "Agbalagba ti ko yokun Awun lo ni" meaning a man without a protruded belly is stingy, in Nigeria fat belly increase the confidence of a man and makes him feel important, because he knows that wherever he goes, he will be accepted and respected, a false sense of achievement.

\section{Causes of obesity}

The mechanism behind obesity is multifactorial, lifestyle preference and cultural environment plays a significant role in the incidence of obesity, a sedentary life style, genetic influence, hormonal disorder also cannot be ruled out.

Genetic Factor:- It has been observed that obesity runs in a family, this might be due to genetic influence, however gene alone do not always predicts obesity it will require outside factors such as plenty food supply and restraint activity.

Dietary Behaviour:- Eating habits and weight gain are directly proportional, hardly one will see obese person that doesn't like food, because every single cell in the body has to be fed and nourished, they eat and overeat with both hands, they accumulate food and so fat is accumulated in the body. 


\section{Reduced Physical Activity}

Inadequate physical exercise and energy output often leads to obesity, today, our schedule of spending hours watching movies, indulging in reading of books, unwilling to trek a short distance, but always prefer to go places on a motor bike (the new trend of mobility in Nigeria these days), all these factors do influence obesity.

Environmental Influence:- People often times live their lives based on what is around them and make decisions based on their environment. Lifestyle of what is available to eat, means of transportations, peer group is often determined by environment.

Disease \& Drugs:- Some illness may trigger obesity or weight increase, these may include Cushing disease and polycystic ovary syndrome, it has been reported that drugs like anti depressant steroids may cause weight gain.

\section{Classification of Obesity}

We have two type of obesity

1. Android Obesity:- This is the accumulation of fat on the upper part of the body in the chest and abdomen, also known as central obesity and this is common with men.

2. Peripheral Obesity or (gynoid) this is the deposit of fat among the hips and thighs and this is common with women.

Hormonal Implications: There are also certain physiological conditions that trigger obesity in women like Pregnancy, Lactation, and Age \& Menopause.

\section{Consequence of Obesity}

The consequence of obesity is very serious \& overwhelming, its adverse effects poses a health, economic and social risks.

Economic Cost: Floor mounted toilets are now being replaced in public toilets Wall mounted toilets facilities by federal government, the purpose of this is to accommodate and support the overweight $\&$ obese patients.

Haulage: Drivers are spending more on fuel to convey more heavily obese passengers, Nigerian taxi drivers charge obese twice the amount they collect from others.

Medicals:- Obese patients patronize hospitals and spend more to treat themselves than other patients.

Low Productivity- Obese person wobble around offices, due to excess fat, obese people are sluggish, lazy and easily get tired. Today many organizations are reluctant to employ them due to their inability to perform at optimal level.

Medical Implications:- People with central obesity that has fat accumulated around the hip and the internal organs might be at risk of developing chronic diseases of lifestyle like hypertension.

Diabetes Mellitus:- It has also been recorded that obesity is linked to type II diabetes when free fatty acids are produced and accumulated in the liver, It inhibits the production of insulin which may leads to hyperinsulinemia.

Metabolic Syndrome:- It is all about insulin resistance which is caused as a result of accumulation of visceral fat which leads to higher level of free fatty acids in the portal circulation.

Osteoarthritis:- Knee osteoarthritis has been evident in obese patients because the impact of body weight exerted across the knee is much greater than any part of body during weightbearing process and it gets worse as patient aged.

\section{Management of Obesity (the way forward)}

All hope is not lost the burden of obesity can be alleviated through proper management and rigorous self discipline. Sadly in my country weight loss is been linked with disease and not better health, we must combat obesity and to lose weight is not easy, one thing is to lose weight another thing is to maintain the loss. 
South American Journal of Public Health

Special Edition May 2016

Education:- There is need to educate the Nigerian citizen in general, this includes partners/spouses, parents, children, extended family members and peers regarding the health $\&$ social risks associated with obesity.

\section{Collective Effort:-}

To win this battle we must loose, there is need for a permanent change in lifestyle and eating habits and this sometimes is not easily achievable without the social support from friends \& relatives.

Stay active:- Staying active is one of the best way to burn calorie and combat obesity, it is one of the best thing we can do for ourselves, the less time we spend watching Television the better.

Dietary change:- It includes adopting what is called a "prudent diet" which consists of vegetables, fruits, whole grains and we should refrain from fatty food, fast food and habitual drinking of soft drinks after meal.

Regular Exercise: It is not restricted to obese patient alone, regular exercise will better the life of every individual, taking time out, strong will to drop the car and jog regularly that can only make obese people get better and better health wise.

Drug Intake (pharmacotherapy): The sole objective of anti obesity drugs is to reduce appetite. Medication is seen as last resort when other means to reduce weight yield little or no result. Due to the side effects of anti obesity drugs, its use has been strongly discouraged.

Surgical intervention: This has been proved to be useful in severe obesity. Patient who has failed to reduce weight through exercise, diet and medication and he is at obesity related health risk.

The two types of operations include:

Malabsorptive and Restrictive Operations

Malabsorptive operation is also called bariatric operation, malabsorptive procedures is gastric by-pass surgery (GPD) and Billiopancreatic diversion with or without duodenal switch.

Restrictive Operation has to do with reduction of stomach size, patient may experience vomiting, weakness, ulcer, deep veins thrombosis and wound infection after the operation.

The Statistic Approach

A survey was carried out among the medical workers of Federal Medical Centre, a Federal Government Health Institution based in Keffi, 30km from Abuja the Capital city of Nigeria.

Aims and Objectives: The aim of this Project is to discuss Obesity in Nigeria, the Cultural Influence and the way forward on how to curb it.

Objectives:- This study was generally aimed at determining the degree and pattern of obesity using the parameter of Body Mass Index(BMI) among the workers of Federal Medical Centre keffi, Nasarawa State North Central Nigeria.

Method:- It was a descriptive study that spanned over 2 weeks, a total of 156 workers were screened for overweight $\&$ obesity by taking their data of Age, Sex, Marital Status, Occupation, Weight \& Height.

Challenges:- It took a lot of persuasion to be able to have a breakthrough, most people were not just willing to partake in the screening exercise, many said they want to be discreet about their weight, many fat obese claimed they are okay, most of the volunteers were gotten at the triage room (GOPD) where patient are mandated to check their weight, height and to submit for vital signs investigations.

\section{The Demographic characteristic of obese patients}

\begin{tabular}{ll} 
Age & \multicolumn{1}{c}{ Gender } \\
$20-30=08$ & Male $=14$ \\
$31-40=13$ & Female $=34$ \\
$41-50=18$ & \\
$\geq 51=9$ &
\end{tabular}




\section{Occupation}

Doctors -8

Nurses -21

Health Workers $=10$

Others $=9$

\section{Prevalence}

\begin{tabular}{|l|l|}
\hline STATUS & NUMBER\% \\
\hline BMI $\geq 30 \mathrm{~kg} / \mathrm{m}^{2}$ & $48(31 \%)$ \\
\hline BMI $<30 \mathrm{~kg} / \mathrm{m}^{2}$ & $108(69 \%)$ \\
\hline Total & $156(100 \%)$ \\
\hline Class I Obesity (BMI $30-34.9)$ & $27(56.25)$ \\
\hline Class II Obesity (BMI 35-39.9) & $15(31.25)$ \\
\hline Class III Obesity (BMI 40) & $6(12.50)$ \\
\hline Total & $48(100.0)$ \\
\hline
\end{tabular}

\section{Discussion}

Out of 156 workers 48 workers were obese which represents $31 \%$ of total.

108 workers were either over weight or have normal status that represent $69 \%$.

Class I obesity are 17 workers.

Class II obesity 15 workers.

Class III obesity is 6 staff respectively.

Nurses ranked highest among the obese staff and most of them are female followed by staff from other department while the Doctors came out the lowest.

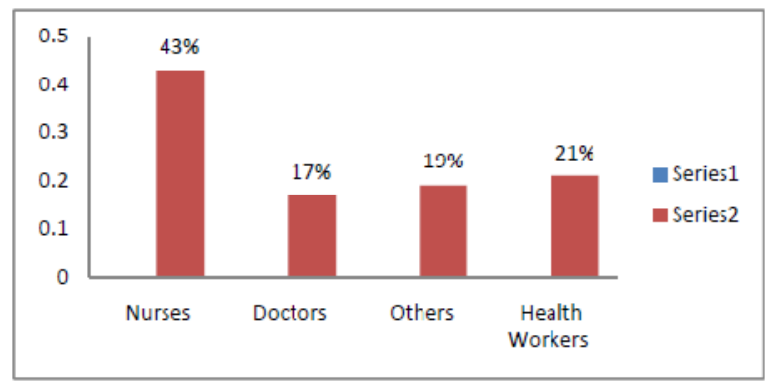

The bar chart of the Data of BMI of the workers of FMC Keffi.

\section{Chart Title}

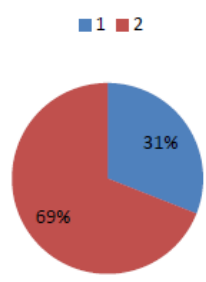

The Pie Chart of the Volunteers, $31 \%$ are Obese while $69 \%$ are overweight or of normal status of weight index

\section{Conclusion}

It is interesting to know that more than half of the staff are overweight, but this is not reflected, since our attention is on obesity and it is also discovered that many of the volunteer did not know what BMI is all about, out of 156 only 8 people claimed to know their BMI, about 10 people also said they know but they never care to check their BMI while about 138 
South American Journal of Public Health

Special Edition May 2016

volunteers which represent $88 \%$ of the total group have no primary knowledge of what BMI is all about.

This is to show that obesity is emerging as a very serious problem in Nigeria and among the study population.

Prevention \& Treatment Campaign: This is where the Government, NGOs and all stakeholders in public health must come out enmass, all the marketing strategies that have been implemented to create social awareness of the adverse effect related to Smoking, Drinking And Driving, Menace Of Abortion, Practice Of Safe Sex, the same tactics should be adopted to fight obesity; an underestimated Silent Killer.

\section{References:}

[1.] Abidoye RO, Izunwa RD, Akinkuade FO, Abidoye GO. Interrelationships between lifestyle and diabetes mellitus, overweight, obesity and hypertension in Nigeria. Nutrition Health 2003; 16:203-13.

[2.] National Task Force on the Prevention and Treatment of Obesity, Overweight and Health Risk. Arch Intern Med 2000; 160:898-904.

[3.] OBESITY: Societal Impression of Good Life, Galleria Health and Lifestyle, Nigeria

[4.] Obesity An underestimated 'silent killer' - Vanguard News

[5.] Obesity in adult Nigerians: A study of its pattern and common primary co-morbidities in a rural Mission General Hospital in Imo state, south-eastern Nigeria

[6.] Obesity And Health : A Review A Case Study By Ogbu C E And Ogbu C S, Nigeria

[7.] Physical Activity: A Key for the Preclusion of Obesity in Children Obesity and Public Health, Texila American University

[8.] The Teen Years Explained: A Guide to Healthy Adolescent Development Obesity: Nutrition and Exercise 